\title{
DPN Treatment plus Annealing Temperatures for 28nm HK/MG nMOSFETs with CHC Stress
}

\author{
Mu-Chun Wang ${ }^{2}$, Shea-Jue Wang ${ }^{1}$, Chii-Wen Chen ${ }^{2, *}$, Hui-Yun Bor ${ }^{3}$, Zhi-Hong Xu ${ }^{2}$ and Wen-How Lan ${ }^{4, *}$ \\ ${ }^{1}$ Dept. of Materials and Resources Engineering, National Taipei University of Technology, Taipei 10608, Taiwan \\ ${ }^{2}$ Dept. of Electronic Engineering, Minghsin University of Science and Technology, Hsinchu 30401, Taiwan \\ ${ }^{3}$ Chung-Shan Institute of Science \& Technology, Taoyuan 32546, Taiwan \\ ${ }^{4}$ Dept. of Electrical Engineering, National University of Kaohsiung, Kaohsiung 81148, Taiwan \\ ${ }^{*}$ Corresponding author
}

\begin{abstract}
The possible nano-crystallization formation and thicker interface layer at the higher annealing atmosphere, however, is easy to suppress the superiority of high-k dielectric deposition in the improvement of drive current and reliability. This phenomenon was apparently observed at $900^{\circ} \mathrm{C}$ annealing tested devices after the nitridation process. The drive current at $900^{\circ} \mathrm{C}$ annealing before hot-carrier stress is lower than that at $700^{\circ} \mathrm{C}$ with the same nitrogen concentration and the same feature sizes. After the hot-carrier stress test at $125^{\circ} \mathrm{C}$ ambience, the degradation of the threshold voltage shift at $900^{\circ} \mathrm{C}$ is still the worst among all of tested samples.
\end{abstract}

Keywords-hot carrier stress; drive current; high-k; MOSFET; anneal; metal-gate; DPN

\section{INTRODUCTION}

The shrinkage of MOSFET channel length and gate dielectric thickness at nano-node process causes more reliability problems if the recent nano-node process technology still follows the $0.13 \mathrm{~m}$ process generation. The gate leakage current increases rapidly when the gate oxide thickness with the growth of silicon dioxide is thinning more. Thus, with bringing in high-k (HK) material [1] as a gate dielectric to solve these former drawbacks is a suitable way. The hafnium-based high-k material $\mathrm{HfZrO}_{\mathrm{x}}$ [2] is one of most promising gate dielectric materials to replace $\mathrm{SiO}_{2}$ or $\mathrm{SiON}$ due to its relatively high dielectric constant, less charge traps, lower interface states, more uniform film quality than pure $\mathrm{HfO}_{2}$, higher nano-crystallization temperature, better thermal stability with silicon, and longer bias temperature instability (BTI) lifetime [3].

Recently, reliability issues of the hafnium-based dielectric such as positive bias-temperature instability (PBTI) and timedependent dielectric breakdown (TDDB) inducing degradation [4] have been extensively investigated. Nevertheless, the channel hot-carrier (CHC) is also one of the main gate dielectric reliability issues. It has not yet been fully and systematically studied, especially the nitridation effect to device performance coming from decoupled plasma nitridation (DPN) process [5] after hot-carrier reliability stress on $\mathrm{HfZrO}_{\mathrm{x}}$ gate dielectrics. To investigate the basic electric characteristics and reliability characteristics with different annealing on hotcarrier injecting into HfZrOx dielectric layer, the $\mathrm{CHC}$ degradation test is made by different stress temperatures and operates on the n-channel MOSFET (nMOSFET) structures with three different channel lengths $(\mathrm{L}=1,0.1$ and $0.03 \mathrm{~m})$.

\section{BRIEF FABRICATION OF NANO-NODE DEVICES}

One simple contour of a nano-planar MOSFET device to demonstrate the cross-sectional device under process fabrication is depicted in Fig. 1. The cardinal structures propose substrate, channel, source/drain (S/D), interfacial layer (IL), high-k with $\mathrm{HfZrO}_{\mathrm{x}}$ formation [6], barrier metal and low-resistivity metal gate. In order to promote the drive current in nMOSFET and pMOSFET, there are two strain technologies in nano-node process possibly adopted: stress memorization technique (SMT) and contact etch stop layer (CESL) process beneficial to nMOSFET device and embedded SiGe S/D plus replacement metal gate (RMG) technique helpful to pMOSFETs. Here is the choice with the latter for pMOSFETs in this work. The entire $28 \mathrm{~nm}$ high-k/metal-gate (HK/MG) process flow with gate-last (GL) process is depicted in Fig. 2 [7].

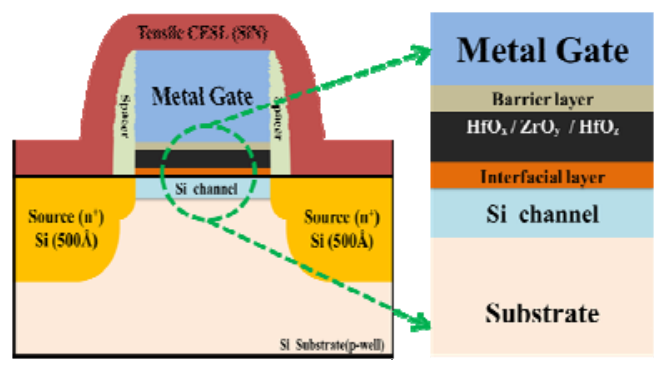

FIGURE I. SCHEMATIC CROSS-SECTION PROFILE OF AN NMOSFET

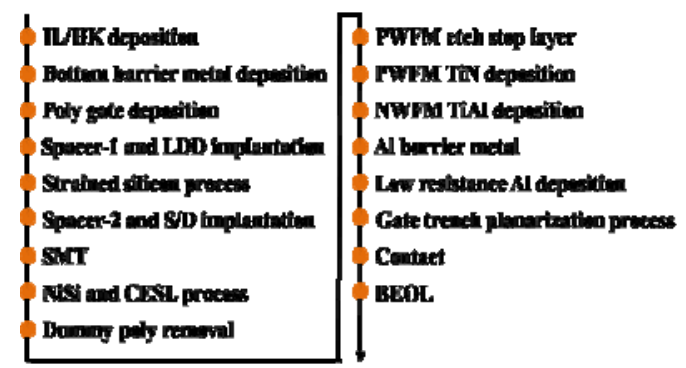

FIGURE II. SIMPLE PROCESS PROCESS FLOW FOR 28NM GATELAST MOSFETS 


\section{Test Results AND Discussion}

In this work, there were two experimental DPN treatment groups: different annealing temperatures $\left(700^{\circ} \mathrm{C}\right.$ and $\left.900^{\circ} \mathrm{C}\right)$ in the nitrogen $\left(\mathrm{N}_{2}\right)$ concentration $(<13 \%)$ atmosphere. One control group with post-deposition annealing (PDA) process in $\mathrm{NH}_{3}$ and under $700^{\circ} \mathrm{C}$ annealing was also included. On the basis of the tested data, as shown in Fig. 3, the roll-up phenomenon of linear threshold voltage $\left(\mathrm{V}_{\mathrm{t}, \text { lin }}\right)$ for nMOSFETs with the constant-current measurement before CHC stress was observed with various channel lengths on different nitridation annealing temperatures. But the $\mathrm{V}_{\mathrm{t}}$ of nMOSFETs should be reversely roll-off as the channel length scaling down according to the previous behaviors in the deep submicron process. For the above phenomenon, it may be explained by using halo implant process to increase threshold voltage and prevent short channel effect from the shrinkage of channel length. While the stress temperature is increased, the $\mathrm{V}_{\mathrm{t}}$ is decreased due to the possible repairs of interface state coming from the thermal energy on the channel surface.

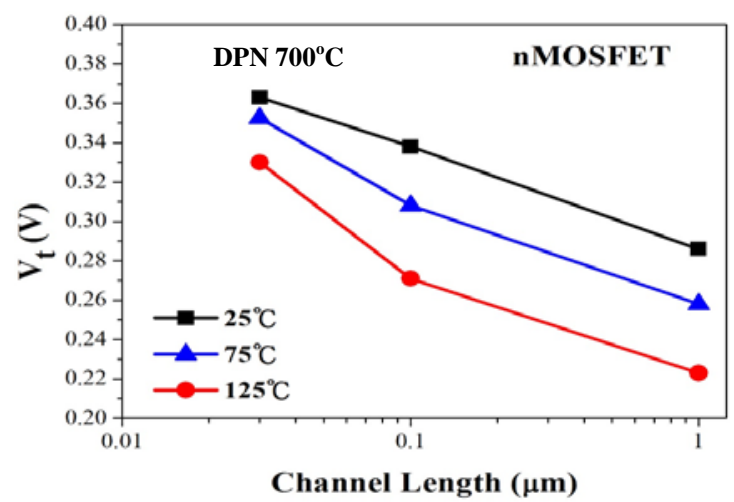

FIGURE III. LINEAR $\mathrm{V}_{\mathrm{t}, \mathrm{I}}$ VS. CHANNEL LENGTHS FOR PDA NMOSFETS UNDER TEMPERATURE STRESS AT 700。C ANNEALING TEMPERATURE

For a saturation drive current of an nMOSFET $\left(\mathrm{I}_{\mathrm{DS}}\right)$, it can be expressed as [8]

$$
I_{D S}=\frac{W}{2 L} \mu_{n} \cdot C_{o x} \cdot\left(V_{G S}-V_{t}\right)^{2} \cdot\left(1+\lambda \cdot V_{D S}\right)
$$

where $\mu_{\mathrm{n}}$ : channel mobility, $\mathrm{C}_{\mathrm{OX}}$ : gate capacitance with unit area and : channel-length modulation factor. To increase the $\mathrm{C}_{\mathrm{OX}}$, the high- $\mathrm{k}$ gate dielectric is adopted into the advanced nano-node process fabrication. The $\mathrm{V}_{\mathrm{t}}$ value can be given as

$$
V_{t}=\Phi_{m s}-\frac{Q_{f}}{C_{o x}}-\frac{Q_{d}}{C_{o x}}+2 \phi_{F}
$$

where ms: work function difference between gate and $\mathrm{Si}$ substrate, $\mathrm{Q}_{\mathrm{f}}$ : fixed charges in gate insulator or interface states between silicon surface and interfacial layer, $\mathrm{Q}_{\mathrm{d}}$ : depletion charges in surface channel, and $\mathrm{q}_{\mathrm{F}}$ : $\mathrm{E}_{\mathrm{i}}$ (intrinsic Fermi level)- $\mathrm{E}_{\mathrm{F}}$ (Fermi level).
In the reliability test, the influenced device parameters chiefly relate to trapping or de-trapping generation on the channel surface or in the gate dielectric. The common discussion focuses on the ON current, $V_{t}, G_{m}$, sub-threshold swing (SS), and device leakage. The trans-conductance $\mathrm{G}_{\mathrm{m}}$ is a good index to probe the interface quality distributed at the channel surface. For a drain current operating at the linear region, it can be expressed as (3) and the $G_{m}$ at the fixed $V_{D S}$ can be given as (4)

$$
\begin{gathered}
I_{D S, \text { lin }}=\frac{W}{L} \cdot \mu \cdot C_{O X}\left(V_{G S}-V_{T}-\frac{V_{D S}}{2}\right) \cdot V_{D S} \\
G_{m}=\left.\frac{\partial I_{D S}}{\partial V_{G S}}\right|_{V_{D S}=0.05 V}=\frac{W}{L} \cdot \mu \cdot C_{O X}
\end{gathered}
$$

When we discuss the device performance, the parameter, subthreshold swing (SS), should be introduced due to the index of interface quality and the off-leakage such as gateinduced drain leakage effect as well as the switching quality for this device. The SS can be defined as

$$
S S=1000\left(\frac{d \log \left(I_{D S}\right)}{d V_{G}}\right)^{-1}=2.3 \frac{k T}{q}\left(1+\frac{C_{d}+C_{i t}}{C_{O X}}\right) 1000
$$

where k: Boltzmann constant, $\mathrm{T}$ : absolute temperature, $\mathrm{C}_{\mathrm{d}}$ : depletion capacitance in channel surface, and $\mathrm{C}_{\mathrm{it}}$ : equivalent interface-state capacitance. The unit of $\mathrm{SS}$ is $\mathrm{mV} /$ decade.

Before the stress, the initial characteristics of drive currents with channel lengths $(\mathrm{L}=0.03,0.1$, and $1 \mu \mathrm{m})$ as channel width $\mathrm{W}=1 \mu \mathrm{m}$ are exhibited in Fig. 4. The difference of $\mathrm{ON}$ current at $\mathrm{L}=1 \mu \mathrm{m}$ is specially illustrated in Fig.5. The tested devices with different treatment temperatures in nitridation demonstrate the similar performance for the long-channel devices, but the drive current with PDA nitridation is gradually better than the others as the channel length is shortened due to the contribution of $\mathrm{Si}-\mathrm{H}$ bonds on the channel surface. This evidence also shows in Fig. 6. Lower interface state; higher channel mobility.

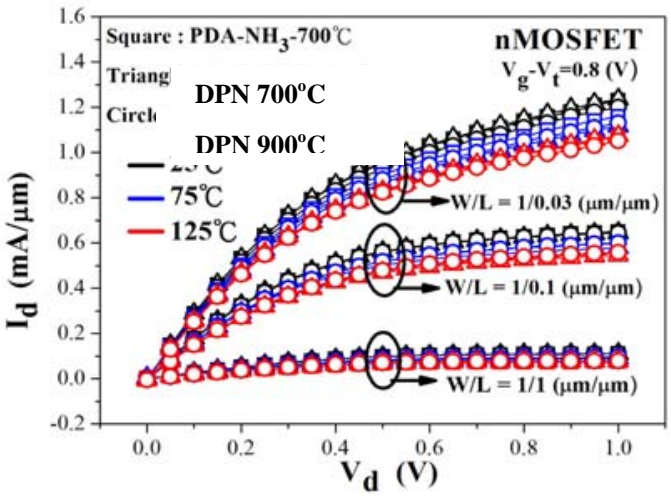

FIGURE IV. DRIVE CURRENTS WITH DIFFERENT TESTED DEVICES AT 25,75 , AND $1250 \mathrm{C}$ 
However, as the stress temperature is increased, the channel scattering is also increased, inducing the degradation of channel mobility proved by the trans-conductance $\left(\mathrm{G}_{\mathrm{m}}\right)$ results with $\mathrm{W} / \mathrm{L}=1 / 0.03(\mu \mathrm{m} / \mu \mathrm{m})$, as shown in Fig. 6 . The whole variation with different tested devices at the maximum $\mathrm{G}_{\mathrm{m}}\left(\mathrm{G}_{\mathrm{m} \text { max }}\right)$ is shown in Fig. 7. While the channel length is longer, the $G_{m \_ \text {max }}$ is not easily influenced by the increase of temperature. Because of the increase of the degradation amount if they are similar, the impact to the degradation of the drive current is not serious. The change of $\mathrm{G}_{\mathrm{m} \_ \text {max }}$ at the long channel device is relatively small. On the contrary, the impact is increased in contrast to the short channel device.

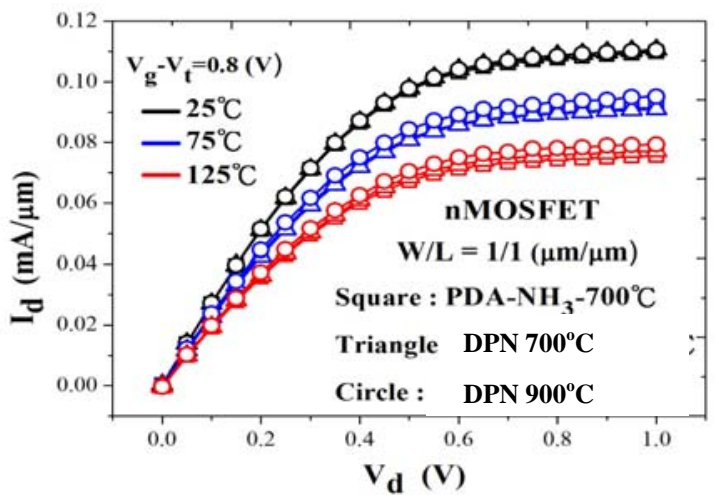

FIGURE V. DRIVE CURRENTS WITH W/L=1/1 $(\mu \mathrm{m} / \mu \mathrm{m})$ AT 25,75 , AND $125 \mathrm{oC}$

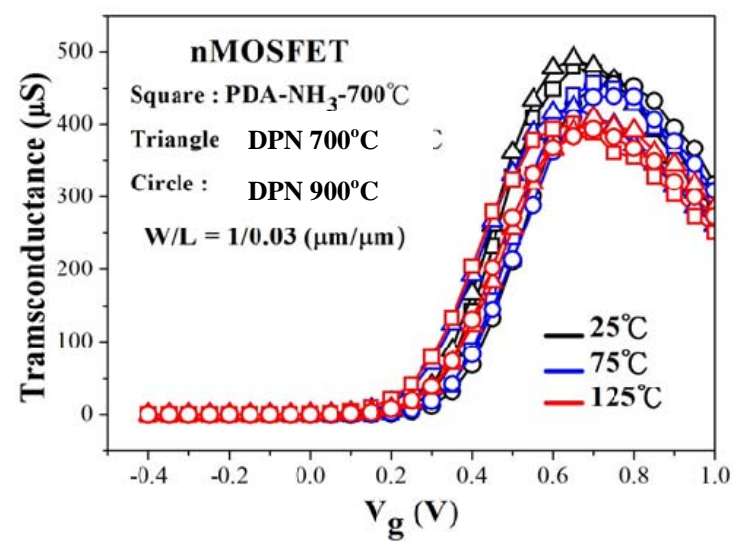

FIGURE VI. ILLUSTRATION OF Gm WITH W/L=1/0.03 $(\mu \mathrm{m} / \mu \mathrm{m})$ AT 25 ,

$$
75 \text {, AND } 125 \mathrm{oC}
$$

When the $V_{t}$ change is seen, as shown in Fig. 8 and 9, the cardinal dominant is the fixed charge usually related to the number of interface state $\left(\mathrm{N}_{\mathrm{it}}\right)$ by unit area, oxide trap $\left(\mathrm{N}_{\mathrm{ot}}\right)$, or both, as shown in Fig. 10. Because the hot carrier stress impacts the shorter device more, we focus on the tested device with $\mathrm{W} / \mathrm{L}=1 / 0.03(\mu \mathrm{m} / \mu \mathrm{m})$. At room temperature, the maximum $V_{t}$ shift is with DPN $700^{\circ} \mathrm{C}$ condition. The $V_{t}$ shift with DPN $900^{\circ} \mathrm{C}$ is the minimum, as shown in Fig. 8 . However, the case at $125^{\circ} \mathrm{C}$ stress is fully reversed, as shown in Fig.9, due to the increased degradation of channel mobility, illustrated in Fig. 6. The CHC stress condition was the stress voltage $\mathrm{V}_{\text {stress }}=1.4 \mathrm{~V}_{\mathrm{cc}}+\mathrm{V}_{\mathrm{t}}$ as $\mathrm{V}_{\mathrm{cc}}=0.8 \mathrm{~V}, \mathrm{~V}_{\mathrm{g}}=\mathrm{V}_{\mathrm{d}}=\mathrm{V}_{\text {stress }}$ and $\mathrm{V}_{\mathrm{b}}=\mathrm{V}_{\mathrm{s}}=0 \mathrm{~V}$ as well as the stress temperatures 25,75 , and 125
${ }^{\circ} \mathrm{C}$. After 3000s CHC stress, the $\mathrm{V}_{\mathrm{t}}$ shift of the tested devices with different annealing temperatures will be exposed more.

According to (5), the difference of $\mathrm{C}_{\mathrm{it}}=\mathrm{q} \mathrm{D}_{\mathrm{it}}$ before and after stress can be extracted as [9].

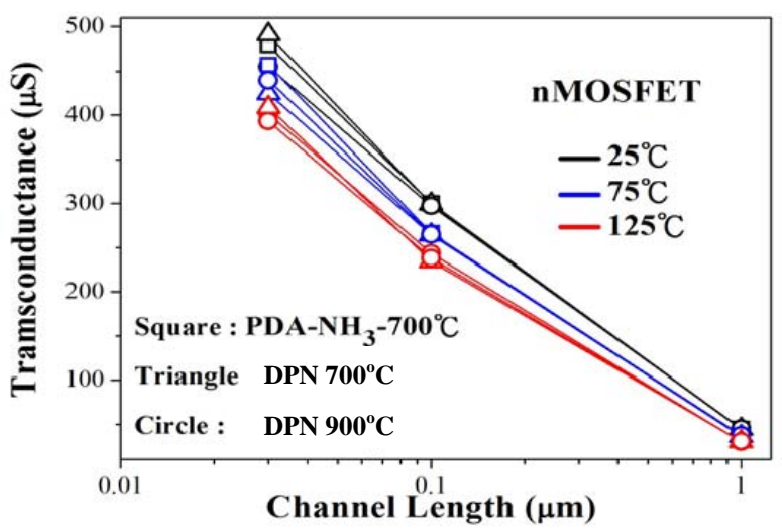

FIGURE VII. MAXIMUM Gm WITH CHANNEL LENGTHS AT 25, 75, AND $125 \mathrm{oC}$

$$
N_{i t}=\int_{E_{V}}^{E_{C}} D_{i t} \cdot d E \approx D_{i t} \cdot E_{i t}
$$

$$
\Delta N_{i t}=\frac{\Delta S S \cdot C_{O X} \cdot E_{i t}}{2.3 \cdot k T \cdot 1000}
$$

where $D_{i t}$ : interface state density and $E_{i t}:\left(E_{i}-E_{F}\right)$.

The fixed charges in device are probably classified as $\mathrm{N}_{\mathrm{it}}$ and $\mathrm{N}_{\mathrm{ot}}$, excluding the mobile ion contribution. The total change of charge number $\mathrm{N}_{\text {tot }}$ is basically equal to ( $\mathrm{N}_{\mathrm{it}}+\mathrm{N}_{\mathrm{ot}}$ ).

$$
\Delta N_{\text {tot }}=\frac{\Delta V_{t} \cdot C_{O X}}{q}
$$

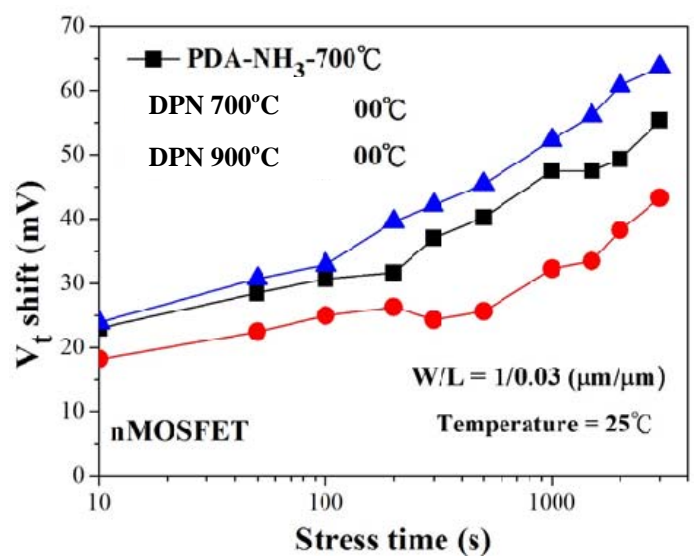

FIGURE VIII. $\mathrm{V}_{\mathrm{t}}$ VS. STRESS TIME AT ROOM TEMPERATURE 


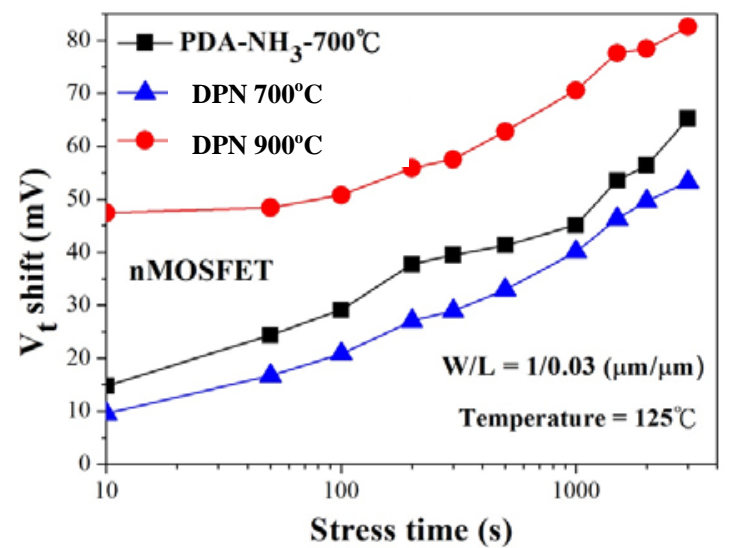

FIGURE IX. $V_{t}$ VS. STRESS TIME AT 125oC.

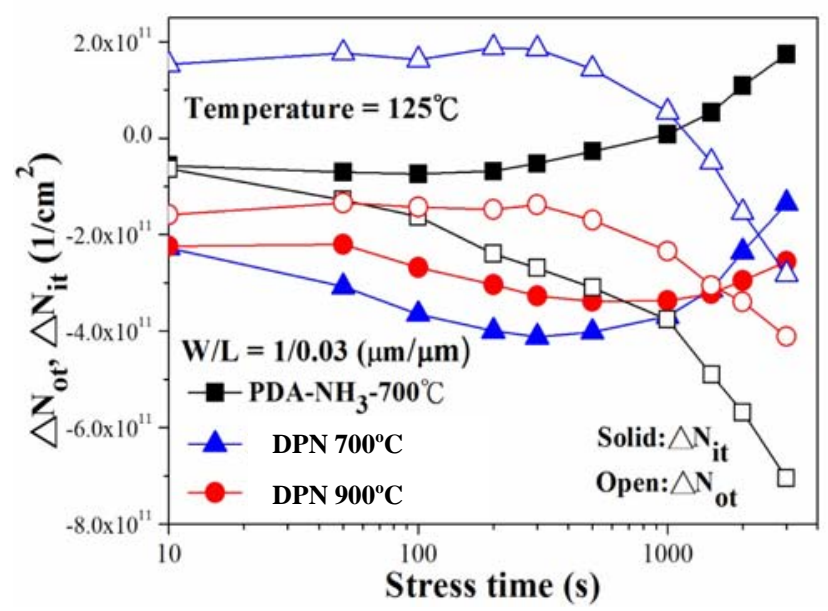

FIGURE X. DISTRIBUTION OF $\mathrm{N}_{\text {IT }}$ AND $\quad \mathrm{N}_{\mathrm{OT}}$ VS. STRESS TIME

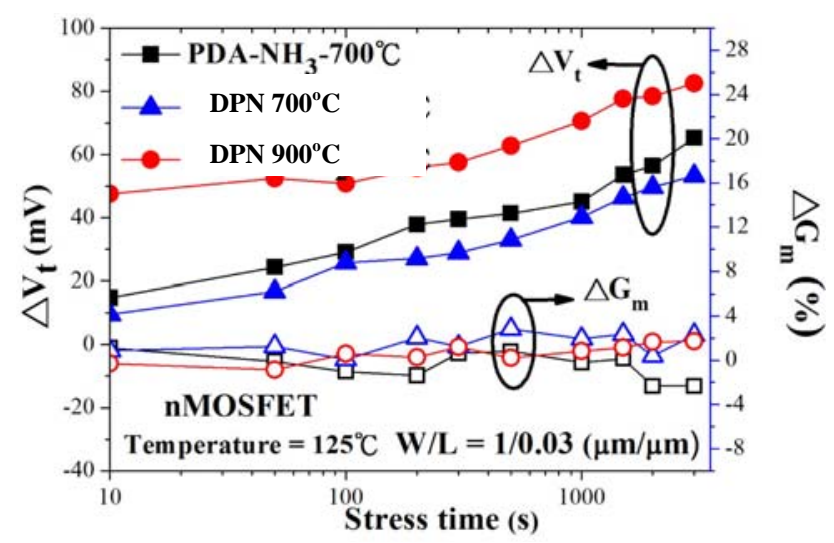

FIGURE XI. $\mathrm{V}_{\mathrm{t}}$ SHIFT AND $\mathrm{G}_{\mathrm{m}}$ CHANGE VS. STRESS TIME AT $125 \mathrm{oC}$

In Fig. 10, the trends of $\mathrm{N}_{\mathrm{it}}$ and $\mathrm{N}_{\mathrm{ot}}$ are not consistent in stress. For the PDA $700^{\circ} \mathrm{C}$ condition, the hole trapping for

$\mathrm{N}_{\mathrm{it}}$ dominating at the short-time stress gradually moves to the electron trapping, related to the $\mathrm{Si}-\mathrm{H}$ bonds in generation and recombination amount. However, the trend of $\mathrm{N}_{\mathrm{ot}}$ is always dominated by the hole trapping. For the DPN $700^{\circ} \mathrm{C}$, the hole trapping amount for $\mathrm{N}_{\mathrm{it}}$ initially increases, but the change happening when the stress time is increased more due to the increase of the impact ionization. Reversely, the electron trapping for $\mathrm{N}_{\mathrm{ot}}$ shows the stronger influence in the initial stage, but the hole trapping impact is increased as the stress time is increased due to more hole carriers trapped into gate dielectric. For the DPN $900^{\circ} \mathrm{C}$, the trend of $\mathrm{N}_{\mathrm{it}}$ keeps at the hole trapping mechanism and so does the $\mathrm{N}_{\mathrm{ot}}$, but the amount of $\mathrm{N}_{\mathrm{ot}}$ is raised. However, the variation of $\mathrm{N}_{\mathrm{it}}$ and

$\mathrm{N}_{\mathrm{ot}}$ at DPN $900^{\circ} \mathrm{C}$ seems not more serious than that at DPN $700^{\circ} \mathrm{C}$.

In this study, the shortest-channel tested device after $\mathrm{CHC}$ stress represents the largest $V_{t}$ shift with DPN $900^{\circ} \mathrm{C}$ annealing. This effect may be attributed to the higher anneal temperature causing the possible nano-crystallization dielectric and indirectly influencing the device performance in reliability consideration. The dominant factor in degradation should be oxide trap because Fig. 11 provides the evidence illustrating the $\mathrm{G}_{\mathrm{m} \text { max }}$ shift (\%) is not huge no matter what the nitridation treatment is. The distribution profiles of trans-conductance for all before and after test are similar.

\section{CONCLUSION}

Nitrogen plasma is indeed a good recipe to fix the vacancy or oxide trap in high-k gate dielectric. However, the unsuitable control in nitrogen concentration and annealing temperature will degrade the device performance, not only in the initial stage, but in reliability consideration. Using the lower annealing temperature $\left(700^{\circ} \mathrm{C}\right)$ is a good choice to promote the device performance and represent the lower reliability suffering after the $\mathrm{CHC}$ stress. As the stress temperature is increased, the degradation of device performance is distinctly raised due to the extra thermal energy providing more phonon scattering as well as the generation of electron-hole pairs on the channel surface. Basically, The changes of $\mathrm{N}_{\mathrm{it}}$ and $\mathrm{N}_{\mathrm{ot}}$ dominate the degradation of channel integrity. In this work,

$\mathrm{N}_{\text {ot }}$ seems the main role influencing the degradation in device performance, especially in $\mathrm{V}_{t}$ shift. At the higher temperature stress, the DPN $900^{\circ} \mathrm{C}$ shows the maximum degradation in $\mathrm{V}_{\mathrm{t}}$ shift probably attributed to the nanocrystallization in gate dielectric. Next, higher annealing temperature; easily increasing thicker interfacial layer and reducing the $\mathrm{k}$-value in gate dielectric.

\section{ACKNOWLEDGMENT}

The authors sincerely appreciate the United Microelectronics Corporation (UMC) in Taiwan for supporting the advanced wafers and the financial support from National Chung-Shan Institute of Science \& Technology with the project CSIST-706-V302 as well as the College of Engineering at MUST.

\section{REFERENCES}

[1] R. I. Hegde, , "Hafnium zirconate gate dielectric for advanced gate stack applications," Appl. Phys. Lett., vol.101, pp. 074113(1) - 074113(7), Apr. 2007.

[2] H. D. Kim, "Characteristics of high-k gate dielectric formed by the oxidation of sputtered $\mathrm{Hf} / \mathrm{Zr} / \mathrm{Hf}$ thin films on the Si substrate," J. Vac. Sci. Tech., vol. 22, pp. 1342-1346, July 2004.

[3] R.I. Hegde, "Microstructure Modified $\mathrm{HfO}_{2}$ Using $\mathrm{Zr}$ Addition with $\mathrm{Ta}_{\mathrm{x}} \mathrm{C}_{\mathrm{y}}$ Gate for improved device performance and reliability," IEEE IEDM, pp35-38, Dec. 2005. 
[4] Takeshi Watanabe, "Impact of Hf concentration on performance and reliability for HfSiON-CMOSFET," IEEE IEDM, pp. 507-510, Dec. 2004

[5] G. Wilson, "Electron Energy-Dependent Charging Effects of Multilayered Dielectric Materials," IEEE Trans. Plasma Sci., vol.41, iss.12, part:2, pp. 3536 - 3544, 2013.

[6] J. Dekany, "Electron Transport Models and Precision Measurements With the Constant Voltage Conductivity Method," IEEE Trans. Plasma Sci., vol.41, iss.12, part:2, pp. 3565 - 3576, 2013.

[7] C. H. Tsai, "Characteristics of HfZrOx gate stack engineering for reliability improvement on $28 \mathrm{~nm} \mathrm{HK} / \mathrm{MG}$ CMOS technology," IEEE VLSI-TSA, pp.1-2, Apr. 2012.

[8] S.M. Sze, Semiconductor Devices Physics and Technology, $2^{\text {nd }}$ ed., John Wiley \& Sons, Inc., New Jersey, USA, 2002.

[9] D. Neamen, An introduction to Semiconductor Devices, $1^{\text {st }}$ ed., McGraw Hill, New York, 2006. 